\title{
Sciendo
}

\section{MICROECONOMIC FOUNDATION OF THE PHILLIPS CURVE}

\author{
Yasuhito TANAKA* \\ Doshisha University, Japan
}

\begin{abstract}
It is an important problem to derive negative relation between the unemployment rate and the inflation rate, that is, the Phillips curve without market imperfection. We derive the Phillips curve using an overlapping generations model under monopolistic competition. We consider the effects of exogenous changes in labor productivity. An increase (decrease) in the labor productivity in a period induces a decrease (increase) in the employment, an increase (decrease) in the unemployment rate and a falling (rising) in the price of the goods in the same period. Then, given the price in the previous period the inflation rate falls (rises). This conclusion is based on the premise of utility maximization of consumers and profit maximization of firms. Therefore, we have presented a microeconomic foundation of the Phillips curve.
\end{abstract}

JEL classifications: E12, E24, E31

Keywords: Phillips Curve, Microeconomic foundation, Overlapping generations model, Monopolistic competition.

\section{Introduction}

Otaki and Tamai (2012) presented a microeconomic foundation of the negative relation between the unemployment rate and the inflation rate, that is, the Phillips Curve (Phillips (1958)) using an overlapping generations model (OLG model) under monopolistic competition. They have shown that, the lower the unemployment rate in a period (for example period $t-1$ ), the higher the inflation rate from period $t$ to period $t+1$. Their logic is as follows. They assume that the low (or high) unemployment rate in period $t-1$ raises (or lowers) the labor productivity in period $t$ by learning effect. If the unemployment rate in period $t-1$ increases, the labor productivity in period $t$ falls. Then, by the behavior of firms in monopolistic competition the price of the goods in period $t$ rises given nominal wage rate, and the

\footnotetext{
* Corresponding author. Address: Faculty of Economics, Kamigyo-ku, Kyoto, 602-8580, Japan, yatanaka@mail.doshisha.ac.jp. ORCID 0000-0003-1435-462X
} 
inflation rate from period $t$ to period $t+1$ falls given the (expected) price of the goods in period $t+1$. Alternatively, a decrease in the unemployment rate in period $t-1$ raises the labor productivity in period $t$. Then, the price of the goods falls, and the inflation rate from period $t$ to period $t+1$ rises given the (expected) price of the goods in period $t+1$. However, we do not find their conclusion that the low unemployment rate in period $t-1$ explains the high inflation rate from period $t$ to period $t+1$ to be satisfactory. A fall in the price in period $t$ means that the inflation rate from period $t-1$ to period $t$ falls, that is, the low unemployment rate in period $t-1$ explains the low (not high) inflation rate from period $t-1$ to period $t$.

Instead, in this paper we consider the effects of exogenous changes in labor productivity. It may be due to a change in the unemployment rate in the previous period as assumed by Otaki and Tamai (2012). We will show the negative relationship between the unemployment rate and the inflation rate in the same period. Our logic is as follows. If the labor productivity in a period, for example, period $t$ increases, the employment decreases, and the unemployment rate in period $t$ increases. Then, by the behavior of firms in monopolistic competition the price of the goods falls given nominal wage rate, and the inflation rate from period $t-1$ to period $t$ decreases. Alternatively, if the labor productivity in period $t$ decreases, the employment increases, and the unemployment rate in period $t$ decreases. Then, the price of the goods rises given nominal wage rate, and the inflation rate from period $t-1$ to period $t$ increases.

There are various studies on the theoretical basis of the Phillips curve from the neoclassical and new Keynesian standpoint. The representative of neoclassical studies is Lucas (1972). The neoclassical Phillips curve based on the rational expectations hypothesis is vertical at the natural unemployment rate, but in the short run, incomplete information leads to a downward sloping Phillips curve as firms increase production and employment without realizing that changes in the prices of their goods reflect changes in the general price level. In the new Keynesian analysis, the sticky nature of prices brought about by multi-year wage contracts (Taylor (1979, 1980)) and the sticky pricing behavior of firms (Calvo (1983), Mankiw and Reis (2002)) brings about a downward Phillips curve. Erceg, Henderson and Levin (1998, 2000) develop a similar analysis with a model that incorporates not only price but also wage stickiness, and Woodford (2003) developed an analysis using a model that incorporates an indexation rule such that pricing is linked to the historical inflation rate.

These works on the Phillips curve presumes some market imperfection, and it implies that if there does not exist some price stickiness assumption or imperfect information, the negative correlation between inflation and unemployment will disappear. This paper will show that it is not.

In Section 2 we analyze behaviors of consumers and firms. In Section 3 we consider the equilibrium of the economy with involuntary unemployment. In Section 4 we show the main results about the negative relation between the unemployment rate and the inflation rate.

\section{Behaviors of consumers and firms}

We consider a two-periods (young and old) OLG model under monopolistic competition according to Otaki (2007, 2009, 2011, 2015 and 2016). There is one factor of production, labor, and there is a continuum of goods indexed by $z \in[0,1]$. 
Each good is monopolistically produced by Firm $z$. Consumers are born at continuous density $[0,1] \times[0,1]$ in each period. They can supply only one unit of labor when they are young (period 1).

\subsection{Consumers}

We use the following notations.

$c^{i}(z)$ : consumption of $\operatorname{good} z$ in period $i, i=1,2$.

$p^{i}(z)$ : price of good $z$ in period $i, i=1,2$.

$X^{i}$ : consumption basket in period $i, i=1,2$.

$$
X^{i}=\left\{\int_{0}^{1} c^{i}(z)^{1-\frac{1}{\eta}} d z\right\}^{\frac{1}{1-\frac{1}{\eta}}}, \quad i=1,2, \quad \eta>1 .
$$

$\beta$ : disutility of labor, $\beta>0$.

$W$ : nominal wage rate.

$\Pi$ : profits of firms which are equally distributed to each consumer.

$L:$ employment of each firm and the total employment.

$L_{f}$ : population of labor or employment in the full-employment state.

$y(L)$ : labor productivity. $y(L) \geq 1$.

$\delta$ is the definition function. If a consumer is employed, $\delta=1$; if he is not employed, $\delta=0$. The labor productivity is $y(L)$. We assume increasing or constant returns to scale technology. Thus, $y(L)$ is increasing or constant with respect to the employment of a firm $L$. We define the employment elasticity of the labor productivity as follows.

$$
\zeta=\frac{y^{\prime}}{\frac{y(L)}{L}} .
$$

We assume $0 \leq \zeta<1$. Increasing returns to scale means $\zeta>0 . \eta$ is (the inverse of) the degree of differentiation of the goods. In the limit when $\eta \rightarrow+\infty$, the goods are homogeneous. We assume

$$
\left(1-\frac{1}{\eta}\right)(1+\zeta)<1
$$

so that the profits of firms are positive.

The utility of consumers of one generation over two periods is

$$
U\left(X^{1}, X^{2}, \delta, \beta\right)=u\left(X^{1}, X^{2}\right)-\delta \beta .
$$

We assume that $u\left(X^{1}, X^{2}\right)$ is homogeneous of degree one (linearly homogeneous). The budget constraint is

$$
\int_{0}^{1} p^{1}(z) c^{1}(z) d z+\int_{0}^{1} p^{2}(z) c^{2}(z) d z=\delta W+\Pi .
$$

$p^{2}(z)$ is the expectation of the price of good $z$ in period 2. The Lagrange function is 
$\mathcal{L}=u\left(X^{1}, X^{2}\right)-\delta \beta-\lambda\left(\int_{0}^{1} p^{1}(z) c^{1}(z) d z+\int_{0}^{1} p^{2}(z) c^{2}(z) d z-\delta W-\Pi\right)$.

$\lambda$ is the Lagrange multiplier. The first order conditions are

$$
\frac{\partial u}{\partial X^{1}}\left(\int_{0}^{1} c^{1}(z)^{1-\frac{1}{\eta}} d z\right)^{\frac{\frac{1}{\eta}}{1-\frac{1}{\eta}}} c^{1}(z)^{-\frac{1}{\eta}}=\lambda p^{1}(z)
$$

and

$$
\frac{\partial u}{\partial X^{2}}\left(\int_{0}^{1} c^{2}(z)^{1-\frac{1}{\eta}} d z\right)^{\frac{\frac{1}{\eta}}{1-\frac{1}{\eta}}} c^{2}(z)^{-\frac{1}{\eta}}=\lambda p^{2}(z) .
$$

They are rewritten as

$$
\begin{aligned}
& \frac{\partial u}{\partial X^{1}} X^{1}\left(\int_{0}^{1} c^{1}(z)^{1-\frac{1}{\eta}} d z\right)^{-1} c^{1}(z)^{1-\frac{1}{\eta}}=\lambda p^{1}(z) c^{1}(z), \\
& \frac{\partial u}{\partial X^{2}} X^{2}\left(\int_{0}^{1} c^{2}(z)^{1-\frac{1}{\eta}} d z\right)^{-1} c^{2}(z)^{1-\frac{1}{\eta}}=\lambda p^{2}(z) c^{2}(z) .
\end{aligned}
$$

Let

$$
P^{1}=\left(\int_{0}^{1} p^{1}(z)^{1-\eta} d z\right)^{\frac{1}{1-\eta}}, P^{2}=\left(\int_{0}^{1} p^{2}(z)^{1-\eta} d z\right)^{\frac{1}{1-\eta}} .
$$

They are prices of the consumption baskets in period 1 and period 2. By some calculations we obtain (please see Appendix)

$$
\begin{aligned}
& u\left(X^{1}, X^{2}\right)=\lambda\left[\int_{0}^{1} p^{1}(z) c^{1}(z) d z+\int_{0}^{1} p^{2}(z) c^{2}(z) d z\right]=\lambda(\delta W+\Pi), \\
& \frac{P^{2}}{P^{1}}=\frac{\frac{\partial u}{\partial X^{2}}}{\frac{\partial u}{\partial X^{1}}} \\
& P^{1} X^{1}+P^{2} X^{2}=\delta W+\Pi .
\end{aligned}
$$

The indirect utility of consumers is written as follows

$$
V=\frac{1}{\varphi\left(P^{1}, P^{2}\right)}(\delta W+\Pi)-\delta \beta \text {. }
$$

$\varphi\left(P^{1}, P^{2}\right)$ is a function which is homogeneous of degree one. The reservation nominal wage rate $W^{R}$ is a solution of the following equation.

$$
\frac{1}{\varphi\left(P^{1}, P^{2}\right)}\left(W^{R}+\Pi\right)-\beta=\frac{1}{\varphi\left(P^{1}, P^{2}\right)} \Pi \text {. }
$$

From this

$$
W^{R}=\varphi\left(P^{1}, P^{2}\right) \beta \text {. }
$$


The labor supply is indivisible. If $W>W^{R}$, the total labor supply is $L_{f}$. If $W<W^{R}$, it is zero. If $W=W^{R}$, employment and unemployment are indifferent for consumers, and there exists no involuntary unemployment even if $L<L_{f}$.

Indivisibility of labor supply may be due to the fact that there exists minimum standard of living even in the advanced economy (please see Otaki (2015)).

Let $\rho=\frac{P^{2}}{P^{1}}$. This is the expected inflation rate (plus one). Since $\varphi\left(P^{1}, P^{2}\right)$ is homogeneous of degree one, the reservation real wage rate is

$$
\omega^{R}=\frac{W^{R}}{P^{1}}=\varphi(1, \rho) \beta .
$$

If the value of $\rho$ is given, $\omega^{R}$ is constant.

Otaki (2007) assumes that the wage rate is equal to the reservation wage rate in the equilibrium. However, there exists no mechanism to equalize them. We assume that $\beta$ and $\omega^{R}$ are not so large.

\subsection{Firms}

Let

$$
\alpha=\frac{P^{1} X^{1}}{P^{1} X^{1}+P^{2} X^{2}}=\frac{X^{1}}{X^{1}+\rho X^{2}}, 0<\alpha<1 .
$$

From (3) (7),

$$
\alpha(\delta W+\Pi)\left(\int_{0}^{1} c^{1}(z)^{1-\frac{1}{\eta}} d z\right)^{-1} c^{1}(z)^{-\frac{1}{\eta}}=p^{1}(z)
$$

Since

$$
X^{1}=\frac{\alpha(\delta W+\Pi)}{P^{1}}
$$

we have

$$
\left(X^{1}\right)^{\frac{1}{\eta}-1}=\left(\int_{0}^{1} c^{1}(z)^{1-\frac{1}{\eta}} d z\right)^{-1}=\left(\frac{\alpha(\delta W+\Pi)}{P^{1}}\right)^{\frac{1}{\eta}-1} .
$$

Therefore,

$$
\alpha(\delta W+\Pi)\left(\frac{\alpha(\delta W+\Pi)}{P^{1}}\right)^{\frac{1}{\eta}-1} c^{1}(z)^{-\frac{1}{\eta}}=\left(\frac{\alpha(\delta W+\Pi)}{P^{1}}\right)^{\frac{1}{\eta}} P^{1} c^{1}(z)^{-\frac{1}{\eta}}=p^{1}(z) .
$$

Thus,

$$
c^{1}(z)^{\frac{1}{\eta}}=\left(\frac{\alpha(\delta W+\Pi)}{P^{1}}\right)^{\frac{1}{\eta}} P^{1}\left(p^{1}(z)\right)^{-1} .
$$

Hence,

$$
c^{1}(z)=\frac{\alpha(\delta W+\Pi)}{P^{1}}\left(\frac{p^{1}(z)}{P^{1}}\right)^{-\eta} .
$$


This is demand for good $z$ of an individual of younger generation. Similarly, his demand for good $z$ in period 2 is

$$
c^{2}(z)=\frac{(1-\alpha)(\delta W+\Pi)}{P^{2}}\left(\frac{p^{2}(z)}{P^{2}}\right)^{-\eta} .
$$

Let $M$ be the total savings of consumers of the older generation carried over from their period 1 . It is written as

$$
M=(1-\alpha)\left(\bar{W} \bar{L}+L_{f} \bar{\Pi}\right) .
$$

$\bar{W}, \bar{L}$ and $\bar{\Pi}$ are the nominal wage rate, the employment, and the profit in the previous period. Then, their demand for good $z$ is

$$
\frac{M}{P^{1}}\left(\frac{p^{1}(z)}{P^{1}}\right)^{-\eta} .
$$

The government expenditure constitutes the national income as well as consumptions of younger and older generations. The total demand for good $z$ is written as

$$
c(z)=\frac{Y}{P^{1}}\left(\frac{p^{1}(z)}{P^{1}}\right)^{-\eta} .
$$

$Y$ is the effective demand defined by

$$
Y=\alpha\left(W L+L_{f} \Pi\right)+G+M .
$$

$G$ is the government expenditure (about this demand function please see Otaki (2007), (2009)). The total employment, the total profits and the total government expenditure are

$$
\int_{0}^{1} L d z=L, \int_{0}^{1} \Pi d z=\Pi, \int_{0}^{1} G d z=G .
$$

We have

$$
\frac{\partial c(z)}{\partial p^{1}(z)}=-\eta \frac{Y}{P^{1}} \frac{p^{1}(z)^{-1-\eta}}{\left(P^{1}\right)^{-\eta}}=-\eta \frac{c(z)}{p^{1}(z)} .
$$

From $c(z)=L y(L)$,

$$
\frac{\partial L}{\partial p^{1}(z)}=\frac{1}{y(L)+L y^{\prime}} \frac{\partial c(z)}{\partial p^{1}(z)} .
$$

The profit of Firm $z$ is

$$
\pi(z)=p^{1}(z) c(z)-\frac{W}{y(L)} c(z) .
$$

$P^{1}$ is given for Firm $z$. Note that the employment elasticity of the labor productivity is

$$
\zeta=\frac{y^{\prime}}{\frac{y(L)}{L}} .
$$


The condition for profit maximization with respect to $p^{1}(z)$ is

$$
\begin{aligned}
c(z) & +\left[p^{1}(z)-\frac{y(L)-c(z) y^{\prime} \frac{1}{y(L)+L y^{\prime}}}{y(L)^{2}} W\right] \frac{\partial c(z)}{\partial p^{1}(z)} \\
& =c(z)+\left[p^{1}(z)-\frac{1-L y^{\prime} \frac{1}{y(L)+L y^{\prime}}}{y(L)} W\right] \frac{\partial c(z)}{\partial p^{1}(z)} \\
& =c(z)+\left[p^{1}(z)-\frac{W}{y(L)+L y^{\prime}}\right] \frac{\partial c(z)}{\partial p^{1}(z)}=0 .
\end{aligned}
$$

From this

$$
p^{1}(z)=\frac{W}{y(L)+L y^{\prime}}-\frac{c(z)}{\frac{\partial c(z)}{\partial p^{1}(z)}}=\frac{W}{(1+\zeta) y(L)}+\frac{1}{\eta} p^{1}(z) .
$$

Therefore, we obtain

$$
p^{1}(z)=\frac{W}{\left(1-\frac{1}{\eta}\right)(1+\zeta) y(L)} .
$$

With increasing returns to scale, since $\zeta>0, p^{1}(z)$ is lower than that in a case without increasing returns to scale given the value of $W$.

\section{The equilibrium with involuntary unemployment}

Since the model is symmetric, the prices of all goods are equal. Then,

$P^{1}=p^{1}(z)$.

Hence

$P^{1}=\frac{W}{\left(1-\frac{1}{\eta}\right)(1+\zeta) y(L)}$.

The real wage rate is

$\omega=\frac{W}{P^{1}}=\left(1-\frac{1}{\eta}\right)(1+\zeta) y(L)$.

If $\zeta$ is constant, this is increasing with respect to $L$.

The aggregate supply of the goods is equal to

$W L+L_{f} \Pi=P^{1} L y(L)$.

The aggregate demand is

$\alpha\left(W L+L_{f} \Pi\right)+G+M=\alpha P^{1} L y(L)+G+M$.

Since they are equal,

$P^{1} L y(L)=\alpha P^{1} L y(L)+G+M$, 
or

$$
P^{1} L y(L)=\frac{G+M}{1-\alpha}
$$

In real terms

$$
L y(L)=\frac{1}{1-\alpha}(g+m)
$$

or

where

$$
L=\frac{1}{(1-\alpha) y(L)}(g+m)
$$

$$
g=\frac{G}{P^{1}}, m=\frac{M}{P^{1}}
$$

$\frac{1}{1-\alpha}$ is a multiplier. (12) and (13) mean that the employment $L$ is determined by $g+m$. It can not be larger than $L_{f}$. However, it may be strictly smaller than $L_{f}$ $\left(L<L_{f}\right)$. Then, there exists involuntary umemployment. Since the real wage rate $\omega=\left(1-\frac{1}{\eta}\right)(1+\zeta) y(L)$ is increasing with respect to $L$, and the reservation real wage rate $\omega^{R}$ is constant, if $\omega>\omega^{R}$ there exists no mechanism to reduce the difference between them.

\section{Phillips Curve}

\section{1 Exogenous change in labor productivity}

We consider exogenous changes in labor productivity given nominal wage rate. It may be due to a change in the unemployment rate in the previous period as assumed by Otaki and Tamai (2012). Suppose that the labor productivity $y(L)$ in a period, for example, period $t$ increases to $\theta y(L)$ with a constant $\theta>1$ given $L$. From (13) if $g$ and $m$ are constant, employment $L$ decreases, that is, the unemployment rate in period $t$ increases. (9) means that the price of the goods in period $t$ given $W$ falls because nan $\zeta$ are constant. Let $P_{t}$ and $P_{t-1}$ be the price of the goods (price of the consumption basket) in period $t$ and that in period $t-1$. Then, the inflation rate from period $t-1$ to $t, \frac{P_{t}}{P_{t-1}}-1$, falls given $P_{t-1}$.

Alternatively, a decrease in the labor productivity $(\theta<1)$ increases employment, decreases the unemployment rate, and raises the price of the goods and the inflation rate from period $t-1$ to $t$.

Therefore, we obtain the negative relationship between the unemployment rate and the inflation rate in the same period.

Figure 1 depicts an example the Phillips Curve. $U_{t}$ denotes the unemployment rate in period $t$. 
Figure 1: Phillips Curve

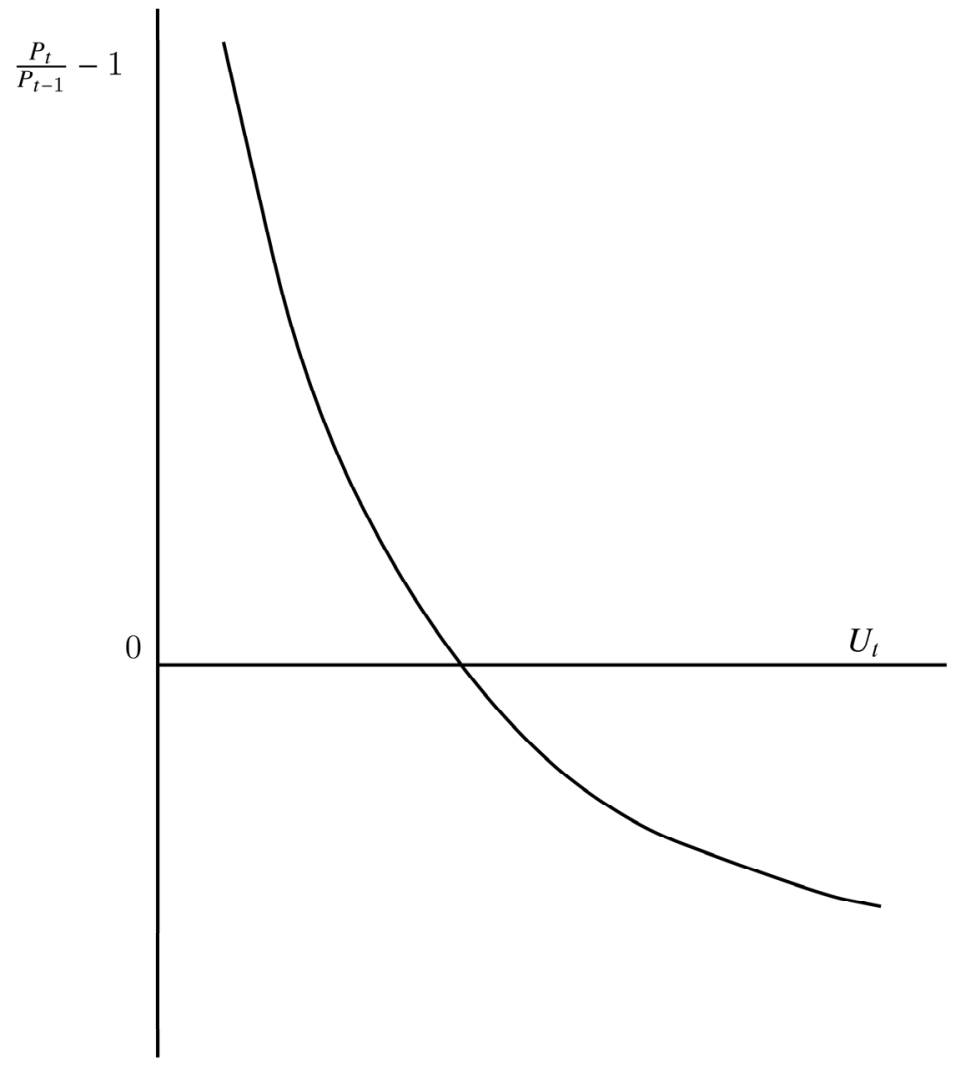

\subsection{Analysis by Otaki and Tamai (2012)}

Otaki and Tamai (2012) suppose that the low (or high) unemployment rate in a period, for example, period $t-1$ raises (or lowers) the labor productivity in period $t$ by learning effect. If the unemployment rate in period $t-1$ increases, the labor productivity in period $t$ falls. Then, from (9) the price of the goods rises, and the inflation rate from period $t$ to period $t+1$ falls given the (expected) price of the goods in period $t+1$. Alternatively, a decrease in the unemployment rate in period $t-1$ raises the labor productivity in period $t$. Then, the price of the goods falls, and the inflation rate from period $t$ to period $t+1$ rises given the (expected) price of the goods in period $t+1$. Thus, they have shown the negative relation between the unemployment rate in period $t-1$ and the inflation rate from period $t$ to period $t+1$, $\frac{P_{t+1}}{P_{t}}-1$. On the other hand, a fall in the price in period $t$ means that the inflation rate from period $t-1$ to period $t$ falls, that is, the low unemployment rate in period $t-1$ explains the low (not high) inflation rate from period $t-1$ to period $t, \frac{P_{t}}{P_{t-1}}-1$. 
Their Phillips curve is depicted in Figure 2. $U_{t-1}$ denotes the unemployment rate in period $t-1$.

Figure 2: Phillips curve by Otaki and Tamai (2012)

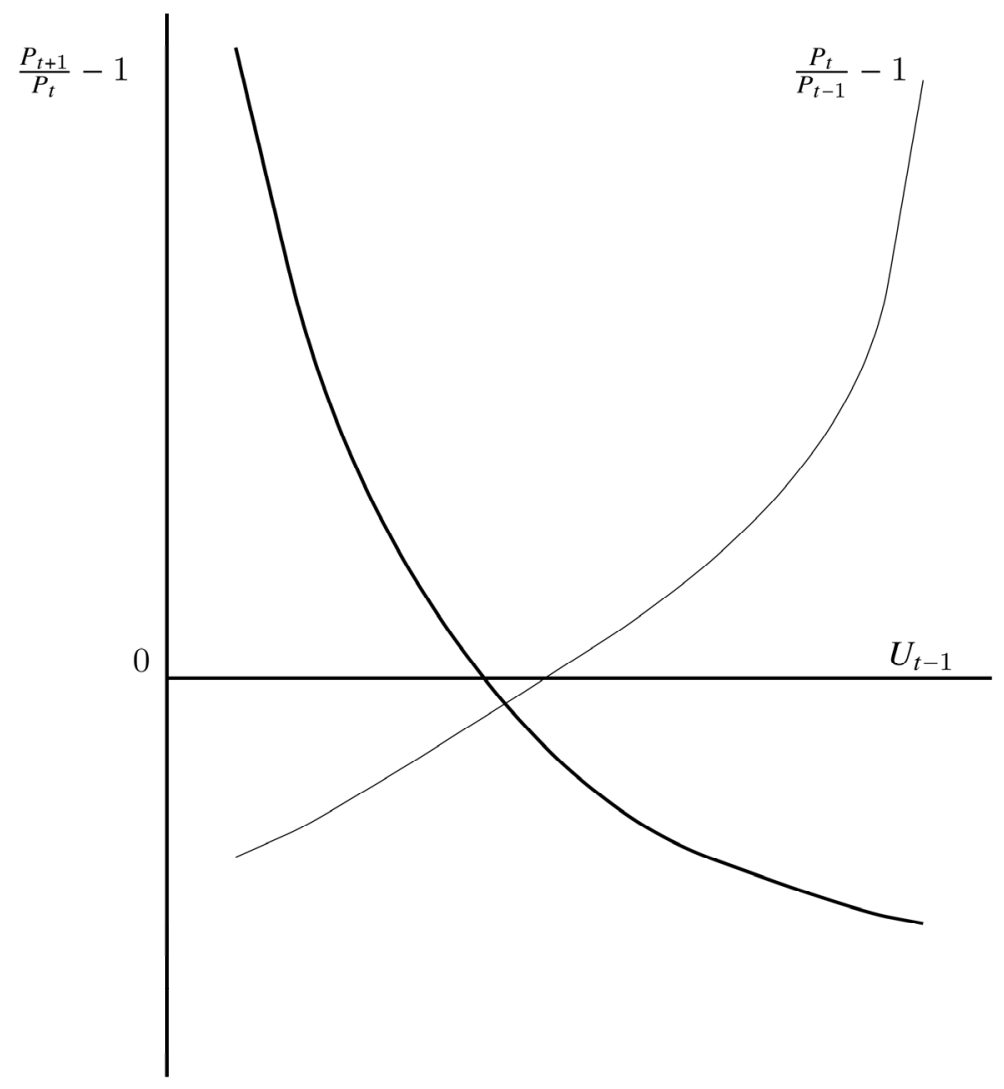

\section{Conclusion}

We have shown that in an overlapping generations model under monopolistic competition changes in labor productivity bring about the negative relation between the unemployment rate and the inflation rate in the same period. This conclusion is based on the premise of utility maximization of consumers and profit maximization of firms. Therefore, we have presented a microeconomic foundation of the Phillips curve.

As I mentioned in the introduction, much of the previous literature on the Phillips curve assumed some form of economic incompleteness, such as price rigidity or incomplete information, but I believe the greatest contribution of this paper is that it shows the existence of a negative correlation between prices and the unemployment rate without making such assumptions. 
The policy implications of this study are as follows.By equation (13), we can see that an increase in government spending at a given price leads to an increase in employment and output. In Figure 1, this is expressed as a shift of the Phillips curve to the left. In the case of increasing returns to scale, prices may decrease, but employment and output will still increase.

The limitation of our analysis is the assumption that the goods are produced only by labor. Future research could analyze the Phillips curve relation in an economy with capital and labor, and there exist investments of firms.

\section{Acknowledgment}

The author would like to thank the referees for their helpful comments. They have greatly improved the paper. This work was supported by the Japan Society for the Promotion of Science KAKENHI Grant Number 18K01594.

\section{Appendix: Derivations of (5), (6), (7) and (8)}

From (3) and (4)

$$
\begin{aligned}
& \frac{\partial u}{\partial X^{1}} X^{1}\left(\int_{0}^{1} c^{1}(z)^{1-\frac{1}{\eta}} d z\right)^{-1} \int_{0}^{1} c^{1}(z)^{1-\frac{1}{\eta}} d z=\frac{\partial u}{\partial X^{1}} X^{1}=\lambda \int_{0}^{1} p^{1}(z) c^{1}(z) d z, \\
& \frac{\partial u}{\partial X^{2}} X^{2}\left(\int_{0}^{1} c^{2}(z)^{1-\frac{1}{\eta}} d z\right)^{-1} \int_{0}^{1} c^{2}(z)^{1-\frac{1}{\eta}} d z=\frac{\partial u}{\partial X^{2}} X^{2}=\lambda \int_{0}^{1} p^{2}(z) c^{2}(z) d z .
\end{aligned}
$$

Since $u\left(X^{1}, X^{2}\right)$ is homogeneous of degree one,

$$
u\left(X^{1}, X^{2}\right)=\frac{\partial u}{\partial X^{1}} X^{1}+\frac{\partial u}{\partial X^{2}} X^{2} .
$$

Thus, we obtain

$$
\frac{\int_{0}^{1} p^{1}(z) c^{1}(z) d z}{\int_{0}^{1} p^{2}(z) c^{2}(z) d z}=\frac{\frac{\partial u}{\partial X^{1}} X^{1}}{\frac{\partial u}{\partial X^{2}} X^{2}},
$$

and

$$
u\left(X^{1}, X^{2}\right)=\lambda\left[\int_{0}^{1} p^{1}(z) c^{1}(z) d z+\int_{0}^{1} p^{2}(z) c^{2}(z) d z\right]=\lambda(\delta W+\Pi) .
$$

From (1) and (2), we have

$$
\left(\frac{\partial u}{\partial X^{1}}\right)^{1-\eta}\left(\int_{0}^{1} c^{1}(z)^{1-\frac{1}{\eta}} d z\right)^{-1} c^{1}(z)^{1-\frac{1}{\eta}}=\lambda^{1-\eta} p^{1}(z)^{1-\eta},
$$


and

$$
\left(\frac{\partial u}{\partial X^{2}}\right)^{1-\eta}\left(\int_{0}^{1} c^{2}(z)^{1-\frac{1}{\eta}} d z\right)^{-1} c^{2}(z)^{1-\frac{1}{\eta}}=\lambda^{1-\eta} p^{2}(z)^{1-\eta}
$$

They mean

and

$$
\left(\frac{\partial u}{\partial X^{1}}\right)^{1-\eta}\left(\int_{0}^{1} c^{1}(z)^{1-\frac{1}{\eta}} d z\right)^{-1} \int_{0}^{1} c^{1}(z)^{1-\frac{1}{\eta}} d z=\lambda^{1-\eta} \int_{0}^{1} p^{1}(z)^{1-\eta} d z
$$

$$
\left(\frac{\partial u}{\partial X^{2}}\right)^{1-\eta}\left(\int_{0}^{1} c^{2}(z)^{1-\frac{1}{\eta}} d z\right)^{-1} \int_{0}^{1} c^{2}(z)^{1-\frac{1}{\eta}} d z=\lambda^{1-\eta} \int_{0}^{1} p^{2}(z)^{1-\eta} d z
$$

Then, we obtain

$$
\frac{\partial u}{\partial X^{1}}=\lambda\left(\int_{0}^{1} p^{1}(z)^{1-\eta} d z\right)^{\frac{1}{1-\eta}}=\lambda P^{1}
$$

and

$$
\frac{\partial u}{\partial X^{2}}=\lambda\left(\int_{0}^{1} p^{2}(z)^{1-\eta} d z\right)^{\frac{1}{1-\eta}}=\lambda P^{2}
$$

From them we get

$$
\begin{aligned}
& u\left(X^{1}, X^{2}\right)=\lambda\left(P^{1} X^{1}+P^{2} X^{2}\right), \\
& \frac{P^{2}}{P^{1}}=\frac{\frac{\partial u}{\partial X^{2}}}{\frac{\partial u}{\partial X^{1}}}
\end{aligned}
$$

and

$$
P^{1} X^{1}+P^{2} X^{2}=\delta W+\Pi \text {. }
$$

Since $u\left(X^{1}, X^{2}\right)$ is homogeneous of degree one, $\lambda$ is a function of $P^{1}$ and $P^{2}$, and $\frac{1}{\lambda}$ is homogeneous of degree one because proportional increases in $P^{1}$ and $P^{2}$ reduce $X^{1}$ and $X^{2}$ at the same rate given $\delta W+\Pi$. We obtain the following indirect utility function.

$$
V=\frac{1}{\varphi\left(P^{1}, P^{2}\right)}(\delta W+\Pi)-\delta \beta .
$$

$\varphi\left(P^{1}, P^{2}\right)$ is a function which is homogenous of degree one. 


\section{References}

Calvo, G. A. (1983) Staggered prices in a utility-maximizing framework. Journal of Monetary Economics, 12, 383-398.

Erceg, C., Henderson D. and A. Levin (1998) Trade-offs between inflation and outputgap variances in an optimizing-agent model, International Finance Discussion Papers, Board of Governors of the Federal Reserve System, No.627.

Erceg, C., Henderson D. and A. Levin (2000), Optimal monetary policy with staggered wage and price contracts, Journal of Monetary Economics, 46, 281-313.

Lucas, R.E. Jr. (1972). Expectations and the neutrality of money. Journal of Economic Theory, 4, 103-124.

Mankiw, N. G. and Reis, R. (2002). Sticky information versus sticky prices: a proposal to replace the new Keynesian Phillips curve, Quarterly Journal of Economics, 117, 1295-1328.

Otaki, M. (2007) The Dynamically Extended Keynesian Cross and the WelfareImproving Fiscal Policy. Economics Letters, 96, 23-29.

Otaki, M. (2009) A Welfare Economics Foundation for the Full-Employment Policy. Economics Letters, 102, 1-3.

Otaki, M. (2011) Fundamentals of the Theory of Money and Employment (KaheiKoyo Riron no Kiso (in Japanese). Keiso Shobo.

Otaki, M. (2015) Keynesian Economics and Price Theory: Re-orientation of a Theory of Monetary Economy, Springer.

Otaki, M. (2016) Keynes's General Theory Reconsidered in the Context of the Japanese Economy. Springer.

Otaki, M and M. Tamai (2012) A Microeconomic Foundation for the Phillips Curve under Complete Markets without any Exogenous Price Stickiness: A Keynesian View, Theoretical Economics Letters, 2, 482-486.

Taylor, J. (1979) Staggered wage setting in a macro model. American Economic Review, 69, 108-113.

Taylor, J. (1980) Aggregate dynamics and staggered contracts. Journal of Political Economy, 88, 1-23.

Woodford, M. (2003) Interest and Prices, Princeton University Press. 